\title{
Understanding the Role of Fathers in Children's Physical Activity: A Qualitative Study
}

\author{
Cody D. Neshteruk, Deborah J. Jones, Asheley Skinner, Alice Ammerman, \\ Deborah F. Tate, and Dianne S. Ward
}

\begin{abstract}
Background: Parents are influential in supporting children's physical activity, but relatively little is known about the role of fathers in children's physical activity. Methods: Semi-structured interviews $(n=24)$ were conducted with low-active and active fathers of children 3-11 years old. Deductive thematic analysis was used to identify fathers' physical activity practices and understand how fathers interact with their children around physical activity. Results: All fathers demonstrated coparticipation in physical activity with their children. Other physical activity practices commonly used by fathers included as follows: facilitation of active opportunities, modeling, involvement through coaching or teaching, and encouragement. In addition, fathers viewed physical activity as an opportunity to spend time with their children to bond and develop shared interests. Finally, fathers perceived their role in children's physical activity to be different compared with mothers. Regarding father activity level, active fathers discussed modeling more frequently and tended to engage in a variety of different activities compared with low-active fathers. Conclusions: Fathers play an important role in their children's physical activity, suggesting that physical activity may be one context in which to prompt paternal involvement, foster father-child relationships, and strengthen paternal parenting.
\end{abstract}

Keywords: parenting practices, qualitative, co-participation, family-based

Physical activity contributes to children's healthy growth and development in many areas, including bone development, cardiometabolic health, academic performance, social and emotional health, and reduced adiposity. ${ }^{1,2}$ Despite these benefits many children worldwide fail to meet physical activity recommendations. ${ }^{3}$ Parents play a primary role in children's physical activity through how they structure the physical activity environment (eg, provision of play equipment/toys, available space for play); their own activity behaviors and attitudes; and their use of physical activity parenting practices, which are specific behaviors parents use to support or limit children's physical activity. ${ }^{4-6}$ However, most research has focused on mothers, with little empirical attention devoted to the role of fathers. ${ }^{7,8}$

Although limited research has examined father involvement in children's lifestyle behaviors, physical activity may be a domain where fathers participate more fully. Early in life, fathers more frequently engage in active play with their children, suggesting a natural inclination toward physical activity. ${ }^{9}$ Furthermore, when examining the association between parent and child physical activity, fathers' activity tends to be more often associated with child activity; however, results are mixed, ${ }^{10,11}$ indicating fathers likely influence children's physical activity through other mechanisms. Qualitative studies exploring fathers' physical activity behaviors have shown that fathers perceive they are important role models for physical activity, facilitate children's activity, and

Neshteruk and Skinner are with the Department of Population Health Sciences, Duke University, Durham, NC, USA. Jones is with the Department of Psychology and Neuroscience, University of North Carolina at Chapel Hill, Chapel Hill, NC, USA. Ammerman and Ward are with the Center for Health Promotion and Disease Prevention, University of North Carolina at Chapel Hill, Chapel Hill, NC, USA; and with the Department of Nutrition, University of North Carolina at Chapel Hill, Chapel Hill, NC, USA. Tate is with the Departments of Nutrition and Health Behavior, University of North Carolina at Chapel Hill, Chapel Hill, NC, USA. Neshteruk (cody.neshteruk@duke.edu) is corresponding author. engage in activity with children. ${ }^{12,13}$ In addition, fathers' physical activity parenting practices such as explicit modeling and coparticipation are associated with increased activity in children. ${ }^{14-16}$ Although fathers have not been engaged in family-based interventions, ${ }^{17} 2$ physical activity promotion interventions targeting fathers and their children, Healthy Dads Healthy Kids and Dads and Daughters Exercising and Empowered, found that both father and child activity increased as a result of the interventions. ${ }^{18,19}$

Given the limited observational and intervention evidence, key questions remain about if, to what extent, and how fathers are involved in their children's physical activity. Specifically, we need to better understand the mechanisms through which fathers impact their children's physical activity. Identifying the physical activity parenting practices commonly used by fathers would provide valuable insight into how we can leverage fathers in physical activity promotion interventions. Therefore, the aim of the current study was to characterize fathers' involvement in children's physical activity as well as to identify the physical activity parenting practices commonly used by fathers.

\section{Methods}

Semi-structured interviews were conducted with 24 fathers between October 2016 and April 2017. All study protocols were reviewed and considered exempt by the University of North Carolina at Chapel Hill Institutional Review Board.

\section{Recruitment}

A convenience sample of fathers was recruited through online advertisements; informational emails; and flyers posted in community locations (eg, public libraries, recreation centers). To be eligible, fathers, either biological or nonbiological, had to be at least 18 years old, speak English, have a child between the ages of 
3-11 years, and currently live with the child. Resident fathers of younger children were the focus of this study because they have more opportunity and are likely more involved children's, compared with adolescents' physical activity. If a father had more than one child between the eligible ages, the younger child was chosen as the referent child.

To ensure multiple perspectives were captured, the sample was stratified such that 12 low-active and 12 active fathers were interviewed. During screening, fathers were asked to self-report their own vigorous leisure-time physical activity using a slightly modified validated screener question (ie, How many days per week do you usually do at least 20 min of vigorous physical activity?). ${ }^{20}$ Fathers were classified as active if they indicated engaging in vigorous leisure-time physical activity for at least 20 minutes at least 3 or more days per week. Vigorous leisure-time physical activitywas used to classify fathers' activity level because this type of activity is typically intentional, easier to quantify in a self-reported recall, and has demonstrated better self-report reliability and validity compared with moderate physical activity. ${ }^{21}$ Following screening, eligible fathers were scheduled to complete an in-person interview.

\section{Semi-Structured Interview Guide Development}

To guide interviews, a semi-structured interview guide was developed by members of the research team (C.D.N., D.J.J., and D.S.W.) with expertise in parenting, psychology, physical activity, child development, and qualitative research methods. The Integrative Model of Physical Activity Parenting was used as the guiding theoretical framework for the interview guide. ${ }^{22}$ This model integrates evidence regarding the impact of physical activity parenting on children's physical activity, embedded within the larger socioecological context in which families operate. The parent components of the model were the primary focus of the interview guide and included parent physical activity attributes, perceptions, and practices. The interview guide is shown in Supplementary Table 1 (available online). Questions focused on exploring fathers' physical activity behaviors, views and attitudes, interactions with their children, and practices around physical activity.

\section{Data Collection}

All interviews were conducted by the principal investigator (C.D.N.). Interviews occurred in a private space (eg, conference room or office), and informed consent was obtained prior to the start of the interview. Each interview was audio recorded, and interviews lasted an average of an hour (mean $59.4 \mathrm{~min}$ ). Following the interview, participants completed a brief demographic survey and a physical activity self-report questionnaire (4 items). Two items assessed whether participants engaged in moderate and vigorous physical activity over the past week (yes/no). If participants indicated yes, they were asked to indicate the number of minutes they engaged in each intensity using closed-ended response options (ie, $5 \mathrm{~min}$ or less to $90 \mathrm{~min}$ for vigorous and $10 \mathrm{~min}$ or less to $180 \mathrm{~min}$ for moderate activity). Items were adapted from the International Physical Activity Questionnaire and Behavioral Risk Factor Surveillance System questionnaire, both reliable and valid measures of physical activity. ${ }^{23,24}$ Participants received $\$ 35$ cash for participating.

\section{Data Analysis}

Descriptive statistics (ie, means, SDs, and frequencies) were calculated to describe the sample using SAS (version 9.4; Cary,
NC). Wilcoxon signed-rank tests were used to compare father self-reported moderate and vigorous physical activity. Interviews were transcribed verbatim and then imported into QSR NVivo (version 12; QSR International, Melbourne, Australia) for analysis using a deductive thematic analysis approach. ${ }^{25}$ Two coders (C.D.N. and a research assistant) read each transcript to become familiar with the content. To ensure consistent coding, a codebook was developed using the semi-structured interview guide as well as relevant papers from the physical activity parenting literature. ${ }^{22,26}$ To remain consistent with established literature on physical activity parenting, a list of defined practices developed by Mâsse et $\mathrm{al}^{26}$ was used to guide the identification of physical activity practices. Coding was an iterative process and the codebook was refined as needed. Each transcript was coded independently by the 2 coders and then compared with identify disagreements. The 2 coders met periodically to resolve disagreements and ensure that adherence to the codebook was maintained. Themes were identified and then additional analyses examined these themes to identify differences by father activity level, child sex, and child age.

\section{Results}

Demographic characteristics of the fathers who completed interviews are shown in Table 1. All fathers were biological fathers with an average age of 42.1 years. The majority of fathers were white $(71 \%)$; married/living with a partner $(58 \%)$; had a college or graduate degree $(66 \%)$; were employed full time (83\%); and had an annual family income above $\$ 50,000(58 \%)$. Slightly more than half of the referent children were boys (54\%), and the mean age of children was 7.1 years. Active fathers self-reported more minutes per week of moderate $(95.0$ vs $87.1 ; Z=-0.29 ; P=.76)$ and vigorous $(67.1$ vs $26.3 ; Z=-2.70 ; P<.01)$ physical activity.

Three themes were evident around fathers' physical activity parenting including (1) fathers use of physical activity parenting practices, (2) physical activity in the father-child relationship, and (3) parental roles in children's physical activity. Differences by father activity status, child sex, and child age are noted where present.

\section{Fathers Use of Physical Activity Parenting Practices}

Fathers use and operationalization of physical activity parenting practices are shown in Table 2. Fathers mentioned using 11 out of the 12 defined physical activity parenting practices. ${ }^{26}$ Practices discussed most often by fathers included coparticipation, facilitation, modeling, involvement, and encouragement. Other physical activity parenting practices that were mentioned less frequently included permissiveness, pressuring, guided choice, praise or rewards, expectations, and restrictions for safety or academic concerns. Monitoring children's physical activity was not mentioned by any father.

Coparticipation. All fathers talked about coparticipating in physical activity with their children. Most fathers (21/24) talked about coparticipation in the context of active play or sports, where they would do activities such as play catch or kick a ball in the backyard, wrestle or rough house, or play pretend games. Fathers of younger children (ages 3-6 y) tended to engage in more active play with their children. For instance, one active father of a 6-year-old girl said, "I always try to do fun, silly games. I don't want them to realize we're walking around the block, it's, 'Hey, we're going to learn family football plays and there's gonna be "chicken wing" 


\section{Table 1 Demographic Characteristics of Fathers Participating in Interviews $(n=24)$}

\begin{tabular}{|c|c|}
\hline \multicolumn{2}{|l|}{ Fathers, n (\%) } \\
\hline Age, y & $42.1(9.1)$ \\
\hline \multicolumn{2}{|l|}{ Race } \\
\hline White & $17(71)$ \\
\hline Black & $5(21)$ \\
\hline Other & $2(8)$ \\
\hline Hispanic or Latino & $1(4)$ \\
\hline \multicolumn{2}{|l|}{ Marital status } \\
\hline Married/living with partner & $18(75)$ \\
\hline Single/never married & $4(17)$ \\
\hline Divorced/separated & $2(8)$ \\
\hline \multicolumn{2}{|l|}{ Education } \\
\hline$<$ High school & $3(13)$ \\
\hline High school or GED & $5(21)$ \\
\hline College & $8(33)$ \\
\hline Graduate level & $8(33)$ \\
\hline \multicolumn{2}{|l|}{ Family household income (USD) } \\
\hline$<\$ 25,000$ & $3(13)$ \\
\hline$\$ 25,000-\$ 49,999$ & $7(29)$ \\
\hline$\$ 50,000+$ & $14(58)$ \\
\hline Full-time employment & $20(83)$ \\
\hline \multicolumn{2}{|l|}{ Weight status } \\
\hline Healthy weight $(\mathrm{BMI}<25)$ & $10(42)$ \\
\hline Overweight (BMI 25-29.9) & $10(42)$ \\
\hline Obese $(\mathrm{BMI}>30)$ & $4(17)$ \\
\hline \multicolumn{2}{|l|}{ Children, n (\%) } \\
\hline Boys & $13(54)$ \\
\hline Age, y & $7.1(2.3)$ \\
\hline
\end{tabular}

Abbreviations: BMI, body mass index; GED, general education diploma; SD, standard deviation; USD, United States dollars.

Note: Data are represented as mean(SD).

and "leg wing." ... And I have a little nerf football and they chicken wing and they have to turn one way and I throw them the football and I just try to make it fun" while a low-active father of a 5 -year-old boy said " . . . we will do a lot of playing of hide-andseek, or I become the monster, they run, and I try to catch them, or I became the horse and they jump on me." Fathers of older children (ages 7-11 y), particularly boys, more often discussed engaging in sport-related activities with their children. One active father of an 11-year-old girl, said "Basketball season's about to start, and she will ... when she's in season, we spend time in the driveway playing even when she's not at practice or at games and stuff. Football's the same way. She's playing flag football now, at least one or two days a week we're in the yard throwing the football. She runs, I throw, you know, she runs and throws, I throw and catch." Many fathers (15/24), predominantly active fathers, mentioned going on family walks where children would walk, run, or ride their bikes. Other coactivities often mentioned included riding bikes, exploring nature/hiking, and playing together at the park.

Facilitation. Many fathers (16/24) discussed facilitating children's activity. Some fathers (11/24) enrolled their children in sports (eg, soccer) or classes (eg, dance classes, swimming lessons). One low-active father of a 6-year-old girl referred to organized activities by saying, "It is kind of my domain cause I feel like well I signed "em up."” In many cases, children showed initial interest in the activity and fathers supported this interest by enrolling the child in an organized or structured form of that activity. In other cases, fathers enrolled children, so they could try something new. Fathers also facilitated children's activity by transporting them to sports or classes, which one active father of 5-year-old girl described his role as "play shuttle, play taxi." In addition, some fathers discussed taking children to places where they could be active (eg, parks, outdoor trails) and providing ageappropriate equipment or active toys.

Modeling. Modeling was discussed primarily by active fathers (8/12) compared with low-active fathers (3/12). Active fathers recognized that children are "sponges," observing and remembering what they see, making it important that fathers model healthy behaviors. Some fathers stated that they wanted to "lead by example" or be good role models. For instance, one active father of a 10-year-old girl said "I feel strongly that ... I should lead by example. So, whenever they're at soccer practice, I make sure that I'm there ... running, exercising the entire time they are so they can see." Others fathers talked about specific instances where children would see them doing physical activity and then try to mimic the activity alongside the father.

Involvement. About half of fathers (11/24) discussed involvement in children's physical activity, primarily through coaching or teaching. Some fathers were coaches for their child's sports teams, while others discussed teaching their children specific skills (eg, hitting a ball), showing proper techniques, or how to have fun. One active father of a 6 -year-old boy stated, “. . . what I think of is Dr. Seuss. 'Fun is fun but you have to know how.' And so like I feel like there's a lot of that. Teaching them how to have fun." Some fathers talked about teaching their children to work through adversity to get better or learn new skills.

Encouragement. Fathers who mentioned using encouragement (9/24) mostly reported verbal encouragement to help prompt their children to be active. Fathers often used verbal encouragement to get children to go outside and play. One low-active father of a 4-year-old girl said, "I guess getting her outside as much as we can. You know just encouraging her ... 'Want to come outside with me? Want to help? Come on.' Let her rake through the leaves. Let her pick up stuff from pull gardens and get tomatoes." A few fathers encouraged their children to be active by talking about the benefits of physical activity or pointing out active role models on TV or at sporting events.

\section{Physical Activity in the Father-Child Relationship}

Almost all fathers (22/24) felt that opportunities for physical activity with their children led to a positive, healthier father-child relationship. Being physically active with children was viewed as an opportunity to spend time together by many fathers (18/24). Through this shared time, fathers were able to bond with their children and develop a stronger relationship. One active father of a 6-year-old boy stated, "As I think about my relationship with my son, it's just good to spend time with your kids no matter what you're doing, but the physically activity thing adds another level of bonding" while another active father described physical activity with his 9-year-old daughter as " . . . special daddy daughter kind of time and that's really precious I think to both of us."

Fathers of older children tended to talk more about how the shared time allowed them to develop shared interests with their 


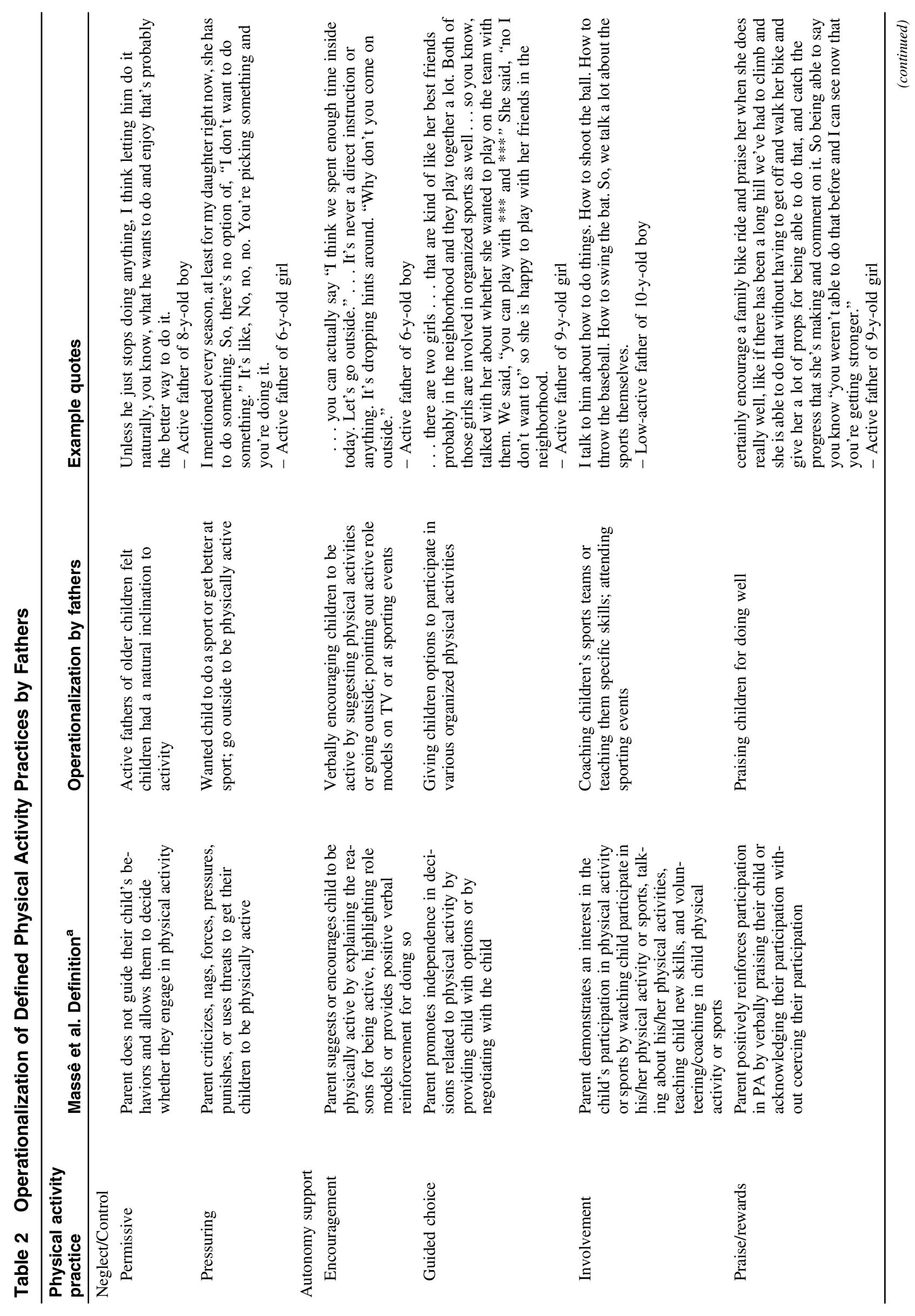




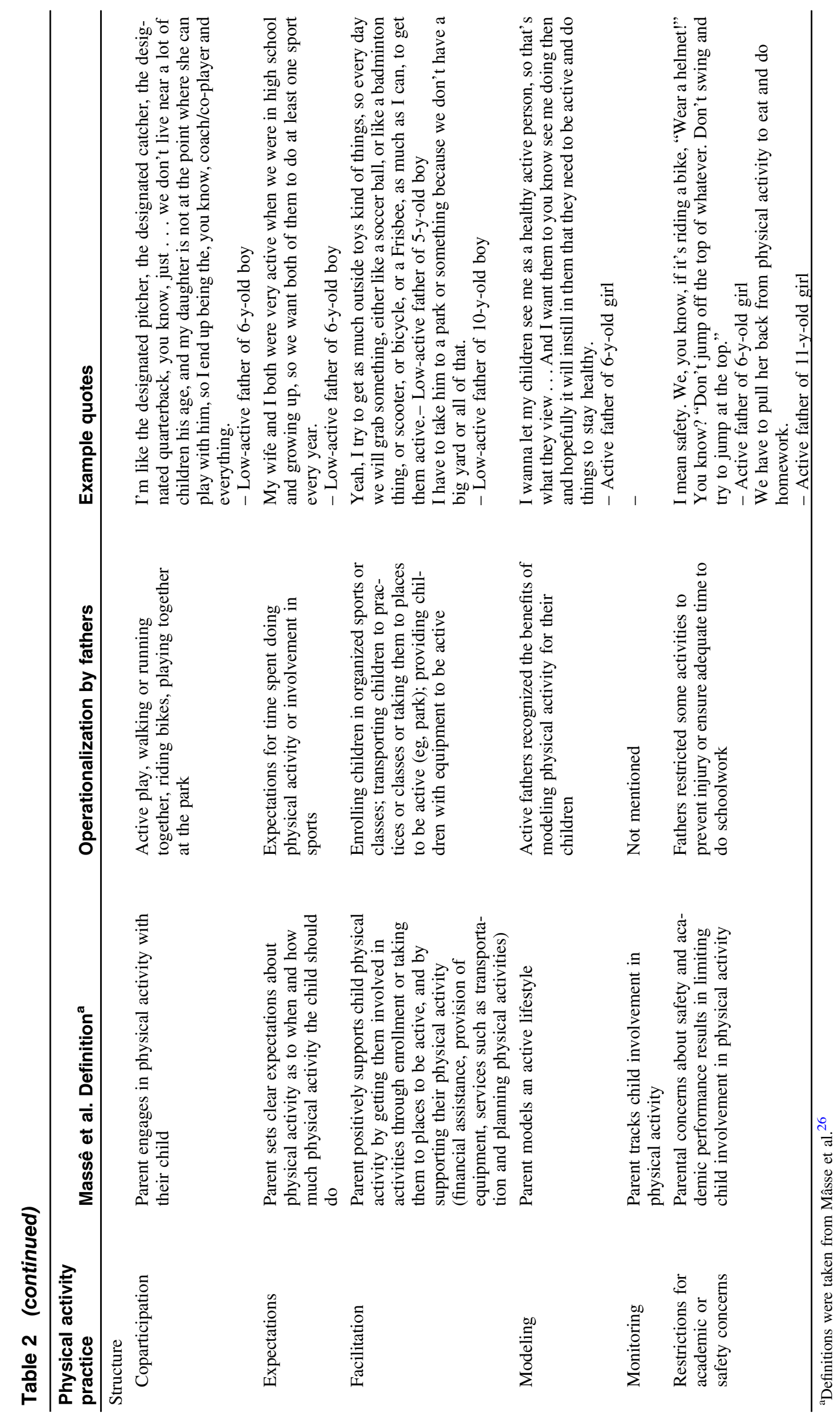


children, particularly around sports. One low-active father of a 10-year-old boy said, "it [physical activity] has developed into the cornerstone. Before it was just by chasing him around, and keeping him from killing himself, just trying to get him fed and changed and all that. As he's gotten older and he's developed interests, a lot of his interest are physical, and so you know when I think of sports, I think of doing them with him." Fathers of younger children more often mentioned shared time as an opportunity for them to help their children learn about themselves and the world around them, which was illustrated by one active father of a 6-year-old girl, “ . . . just the experience the confidence building at the age they're at. I want them to realize that they can do things on their own. It's not, 'I don't wanna try that.' It's like, 'No. No one's here. There are no other kids. Give it a shot. If you fall, I'll catch you.' . . . And, also, the sense of adventure, the sense of exploration, the touching, the feeling, the learning."

\section{Parental Roles in Children's Physical Activity}

Most fathers (18/24) stated that the child's mother was also involved in the child's physical activity; however, maternal involvement tended to be less and different compared with fathers. Compared with mothers, fathers typically described being more actively engaged with their children in doing physical activity. Although many fathers were involved in facilitating activity, they acknowledge that this was often a way mothers were involved, primarily through organizing and coordinating family schedules and transporting children to organized physical activity opportunities (eg, sport practices or games, classes or play dates). One active father of a 6-year-old girl said about the mother, "She obviously helps facilitate a lot in the sense of it's hustling to practices and those things. Um, she is probably not as ... she's nowhere near as active as me." Some fathers $(5 / 24)$ explained that mothers were not as involved in children's physical activity because they took a larger role in other areas (eg, academics, reading, art) or were involved in household tasks such as cooking dinner or taking care of younger children while fathers played with children. One low-active father of a 6-yearold boy stated, "He made a comment recently to my wife, he said ... 'Mommy, you're boring. All you do is cook and clean and fold clothes, and Daddy takes me to games and we do fun stuff.' You know, I hate that he sees it that way, but I mean it is generally our roles . . . between 5:30 and 7 I usually have him and her, or both, and my wife is kind of taking care of more the domestic things."

\section{Discussion}

The role of fathers in children's physical activity has been understudied. This study provides an in-depth exploration with fathers to identify their physical activity parenting practices and understand their involvement in children's physical activity. Findings showed that all fathers, regardless of their own physical activity, are involved in their children's physical activity and use a variety of different physical activity parenting practices, with coparticipation the most frequently cited. In addition, fathers believed that physical activity provided an opportunity to spend time with children, strengthening the father-child relationship and they perceived their role in children's physical activity to be different compared with mothers.

This study provided an opportunity to gain insight into the physical activity parenting practices commonly used by fathers.
Examining current conceptualization of physical activity parenting, practices in the autonomy support/responsiveness (eg, encouragement, involvement) and structure (eg, coparticipation, modeling, facilitation) domains were most often discussed by fathers, while neglecting, controlling, or demanding practices were rarely mentioned. ${ }^{22,26}$ This suggests that fathers support their children's physical activity in a variety of ways. Physical activity promotion programs could capitalize on these supportive practices by providing opportunities for family-based physical activity and by teaching fathers about the importance and benefits of their behaviors in supporting children's physical activity. Furthermore, programs could screen fathers based on their parenting behaviors to identify specific practices and behaviors to focus on.

Coparticipation was an important practice fathers used to support their children's physical activity. This finding is supported by other qualitative studies, ${ }^{12,27}$ along with objective studies showing children's activity increases as a result of parental coparticipation. ${ }^{15,28}$ For instance, in the Healthy Dads Healthy Kids trial, fathers' coparticipation mediated the positive effect of the intervention on children's physical activity. ${ }^{15}$ Furthermore, coparticipation can increase fathers' physical activity, which may be an effective strategy to prevent declines in men's physical activity often associated with fatherhood. ${ }^{29}$ Since all fathers in this study demonstrated some level of coparticipation with their child, this influential practice should be a primary target for family-based physical activity promotion.

Similar to findings in this study, research has shown that physical activity, particularly rough and tumble play, is one of the primary ways that fathers interact with their children. ${ }^{9}$ This type of father-child interaction has been associated with healthy developmental outcomes in children including improved social competence, emotional skills, and self-regulation. ${ }^{30}$ In addition, in one study, participation in a father-daughter physical activity promotion program resulted in improved father-daughter relationship quality and girls' social emotional well-being. ${ }^{19,31}$ Findings in this study support the importance of physical activity in the father-child relationship. One potential explanation is the activation relationship, a theory of father-child attachment that posits children's feelings of confidence result from fathers encouraging children to take risks when exploring their environment. ${ }^{32}$ Fathers who allow their children to take risks around physical activity, while providing a secure base, could strengthen the father-child relationship, assist in the development of motor skills, and promote physical activity. Emphasizing the importance of this relationship and the role of physical activity may be important to consider in both recruitment and programming for family-based physical activity promotion.

Consistent with other studies in the literature, this study showed that fathers and mothers often play different roles in their children's physical activity. ${ }^{4,16,33}$ Interestingly, in a qualitative study with British mothers, researchers found that mothers perceived fathers to be directly involved in children's activity through coparticipation, encouragement, and facilitation, while mothers primarily took on the role of facilitation through logistic support. ${ }^{34}$ These findings mirror the results of our study, showing that both mothers and fathers perceive fathers to be the parent who takes on a more active role in children's physical activity. This indicates that physical activity may be a way to engage fathers in children's health, but also suggests that interventions may need to focus on the entire family. Because of the division of responsibility, mothers may have fewer opportunities for physical activity, which could negatively impact their own health and role modeling behaviors. 
We opted for a stratified sample, hypothesizing that father's activity level may moderate father's interactions with their children around physical activity. However, regardless of activity level, fathers supported their children's physical activity in similar ways. Modeling was one notable exception, with active fathers more often discussing their efforts to model physical activity. It is likely that modeling is an extension of the father's physical activity level, whereas the other commonly used practices (ie, facilitation, involvement, and encouragement) do not require fathers to be physically active, explaining the differences observed in this practice by father activity status.

Previous literature has suggested that differences may exist in how parents interact with their children around physical activity by child sex (eg, fathers more engaged with sons) and age. ${ }^{6}$ There were no differences in fathers use of physical activity parenting practices by child age or sex, but rather differences were evident in the operationalization of some practices. For example, fathers of younger children often engaged in active play, while fathers of older children, engaged in more sports-related activities. This suggests that future studies and family-based interventions need to consider child characteristics when designing programming. In addition, although this study only included one referent child, some fathers with multiple children mentioned differences in their interactions with their children. It may be that differences by child sex and age may be more apparent in families with multiple children.

\section{Limitations/Future Directions}

This study provided valuable insights into the role of fathers in children's physical activity, but there were several limitations. First, although we had representation from both low-active and active fathers, this was a convenience sample, and fathers may have had more positive attitudes toward physical activity. In addition, this sample of biological fathers was mostly affluent and white, limiting the generalizability of our results to more diverse, lower income fathers as well as nonresident fathers and father figures. Another limitation was the reliance on father report alone. Future studies should consider collecting information from fathers as well as mothers and/or children regarding their perceptions of father behavior. In addition, because the maximum child age in this sample was 11 years old, it will be important for future studies to explore the parenting behaviors of fathers with older children, particularly around sports and activities. Finally, physical activity parenting practices were identified using a specific set of defined practices, which may have precluded the identification of additional practices. However, we were able to capture a range of practices, and the set of practices used was extensively developed and intended to guide the physical activity parenting literature that previously suffered from conflicting terminology and inadequately defined parenting behaviors.

\section{Conclusions}

Fathers have been underrepresented in children's health research and family-based interventions. This study shows that fathers play an important role in children's physical activity through their parenting practices and that physical activity participation, in turn, can have a positive impact on the father-child relationship. It will be important to continue exploring differences between mothers and fathers in supporting children's physical activity, but it is evident that physical activity may be a way to engage fathers in their children's health.

\section{Acknowledgments}

We would like to thank Randall Teal and Cindy Kang for their assistance with this project as well as all of the research participants. This project was supported by the National Center for Advancing Translational Sciences (NCATS), National Institutes of Health (NIH), through grant award number UL1TR002489. The content is solely the responsibility of the authors and does not necessarily represent the official views of the NIH. This research was conducted out of the University of North Carolina at Chapel Hill (UNC) Center for Health Promotion and Disease Prevention, which is a Prevention Research Center funded through a Cooperative Agreement with the Centers for Disease Control and Prevention (U48DP005017). Assistance was received from the UNC CHAI Core, which is supported in part by grants from NIH (DK053650) and the National Cancer Institute (P30-CA16086).

\section{References}

1. Janssen I, Leblanc AG. Systematic review of the health benefits of physical activity and fitness in school-aged children and youth. Int $J$ Behav Nutr Phys Act. 2010;7:40. PubMed ID: 20459784 doi:10. 1186/1479-5868-7-40

2. Donnelly JE, Hillman CH, Castelli D, et al. Physical activity, fitness, cognitive function, and academic achievement in children: a systematic review. Med Sci Sports Exerc. 2016;48(6):1223-1224. PubMed ID: 27182987 doi:10.1249/MSS.0000000000000966

3. Roman-Vinas B, Chaput JP, Katzmarzyk PT, et al. Proportion of children meeting recommendations for 24-hour movement guidelines and associations with adiposity in a 12-country study. Int J Behav Nutr Phys Act. 2016;13(1):123. doi:10.1186/s12966-016-0449-8

4. Beets MW, Cardinal BJ, Alderman BL. Parental social support and the physical activity-related behaviors of youth: a review. Health Educ Behav. 2010;37(5):621-644. PubMed ID: 20729347 doi:10. $1177 / 1090198110363884$

5. Xu H, Wen LM, Rissel C. Associations of parental influences with physical activity and screen time among young children: a systematic review. J Obes. 2015;2015:1-23. PubMed ID: 25874123 doi:10. 1155/2015/546925

6. Trost SG, Loprinzi PD. Parental influences on physical activity behavior in children and adolescents: a brief review. Am J Lifestyle Med. 2011;5(2):171-181. doi:10.1177/1559827610387236

7. Davison KK, Gicevic S, Aftosmes-Tobio A, et al. Fathers' representation in observational studies on parenting and childhood obesity: a systematic review and content analysis. Am J Public Health. 2016; 106(11):1980-1980. doi:10.2105/AJPH.2016.303391a

8. Davison KK, Kitos N, Aftosmes-Tobio A, et al. The forgotten parent: fathers' representation in family interventions to prevent childhood obesity. Prev Med. 2018;111:170-176. doi:10.1016/j.ypmed.2018. 02.029

9. Craig L. Does father care mean fathers share? A comparison of how mothers and fathers in intact families spend time with children. Gender Society. 2006;20(2):259-281. doi:10.1177/0891243205285212

10. Neshteruk CD, Nezami BT, Nino-Tapias G, Davison KK, Ward DS. The influence of fathers on children's physical activity: a review of the literature from 2009 to 2015. Prev Med. 2017;102:12-19. PubMed ID: 28652085 doi:10.1016/j.ypmed.2017.06.027

11. Ferreira I, Van Der Horst K, Wendel-Vos W, Kremers S, Van Lenthe FJ, Brug J. Environmental correlates of physical activity in youth-a review and update. Obes Rev. 2007;8(2):129-154. PubMed ID: 17300279 doi:10.1111/j.1467-789X.2006.00264.x

12. Walsh AD, Hesketh KD, van der Pligt $P$, Cameron AJ, Crawford D, Campbell KJ. Fathers' perspectives on the diets and physical activity 
behaviours of their young children. PLoS One. 2017;12(6):e0179210. PubMed ID: 28604810 doi:10.1371/journal.pone.0179210

13. Zhang Y, Hurtado GA, Flores R, Alba-Meraz A, Reicks M. Latino fathers' perspectives and parenting practices regarding eating, physical activity, and screen time behaviors of early adolescent children: focus group findings. J Acad Nutr Diet. 2018;118(11):2070-2080. PubMed ID: 29945853 doi: 10.1016/j.jand.2018.03.025

14. Edwardson CL, Gorely T. Activity-related parenting practices and children's objectively measured physical activity. Pediatr Exerc Sci. 2010;22(1):105-113. PubMed ID: 20332544 doi:10.1123/pes. 22.1.105

15. Lloyd AB, Lubans DR, Plotnikoff RC, Morgan PJ. Paternal lifestylerelated parenting practices mediate changes in children's dietary and physical activity behaviors: findings from the healthy dads, healthy kids community randomized controlled trial. J Phys Act Health. 2015;12(9):1327-1335. PubMed ID: 25526517 doi:10.1123/jpah. 2014-0367

16. Davison KK, Cutting TM, Birch LL. Parents' activity-related parenting practices predict girls' physical activity. Med Sci Sports Exerc. 2003;35(9):1589-1595. PubMed ID: 12972881 doi:10.1249/01. MSS.0000084524.19408.0C

17. Morgan PJ, Young MD, Lloyd AB, et al. Involvement of fathers in pediatric obesity treatment and prevention trials: a systematic review. Pediatrics. 2017;139(2): e20162635. PubMed ID: 28130430 doi:10. 1542/peds.2016-2635

18. Morgan PJ, Collins CE, Plotnikoff RC, et al. The "Healthy Dads, Healthy Kids" community randomized controlled trial: a communitybased healthy lifestyle program for fathers and their children. Prev Med. 2014;61:90-99. PubMed ID: 24380796 doi:10.1016/j.ypmed. 2013.12.019

19. Morgan PJ, Young MD, Barnes AT, Eather N, Pollock ER, Lubans DR. Engaging fathers to increase physical activity in girls: the "dads and daughters exercising and empowered" (DADEE) randomized controlled trial. Ann Behav Med. 2019;53(1):39-52. PubMed ID: 29648571 doi:10.1093/abm/kay015

20. Marshall AL, Smith BJ, Bauman AE, Kaur S. Reliability and validity of a brief physical activity assessment for use by family doctors. $\mathrm{Br} \mathrm{J}$ Sports Med. 2005;39(5):294-297. PubMed ID: 15849294 doi:10. 1136/bjsm.2004.013771

21. Sallis JF, Saelens BE. Assessment of physical activity by self-report: status, limitations, and future directions. Res Q Exerc Sport. 2000; 71(suppl 2):1-14. doi:10.1080/02701367.2000.11082780

22. Davison KK, Mâsse LC, Timperio A, et al. Physical activity parenting measurement and research: challenges, explanations, and solutions. Child Obes. 2013;9(suppl 1):S-103. doi:10.1089/chi.2013.0037
23. Craig CL, Marshall AL, Sjostrom M, et al. International physical activity questionnaire: 12-country reliability and validity. Med Sci Sports Exerc. 2003;35(8):1381-1395. PubMed ID: 12900694 doi:10. 1249/01.MSS.0000078924.61453.FB

24. Pierannunzi C, Hu SS, Balluz L. A systematic review of publications assessing reliability and validity of the Behavioral Risk Factor Surveillance System (BRFSS), 2004-2011. BMC Med Res Methodol. 2013;13(1):49. doi:10.1186/1471-2288-13-49

25. Braun V, Clarke V. Using thematic analysis in psychology. Qual Res Psychol. 2006;3(2):77-101. doi:10.1191/1478088706qp063oa

26. Mâsse LC, O'Connor TM, Tu AW, et al. Conceptualizing physical activity parenting practices using expert informed concept mapping analysis. BMC Public Health. 2017;17(1):574. doi:10.1186/s12889017-4487-1

27. Vollmer RL. An exploration of how fathers attempt to prevent childhood obesity in their families. J Nutr Educ Behav. 2018;50(3): 283-288.e1. PubMed ID: 29524982 doi:10.1016/j.jneb.2017.12.009

28. Rebold MJ, Lepp A, Kobak MS, McDaniel J, Barkley JE. The effect of parental involvement on children's physical activity. J Pediatr. 2016;170:206-210. PubMed ID: 26725460 doi:10.1016/j.jpeds. 2015.11.072

29. Pot N, Keizer R. Physical activity and sport participation: a systematic review of the impact of fatherhood. Prev Med Rep. 2016;4:121-127. PubMed ID: 27413672 doi:10.1016/j.pmedr.2016.05.018

30. Stgeorge J, Freeman E. Measurement of father-child rough-andtumble play and its relations to child behavior. Infant Ment Health J. 2017;38(6):709-725. PubMed ID: 29088498 doi:10.1002/imhj. 21676

31. Young MD, Lubans DR, Barnes AT, Eather N, Pollock ER, Morgan PJ. Impact of a father-daughter physical activity program on girls' social-emotional well-being: a randomized controlled trial. J Consult Clin Psychol. 2019;87(3):294-307. PubMed ID: 30640483 doi:10. 1037/ccp0000374

32. Paquette D, Bigras M. The risky situation: a procedure for assessing the father-child activation relationship. Early Child Dev Care. 2010; 180(1-2):33-50. doi:10.1080/03004430903414687

33. Lloyd AB, Lubans DR, Plotnikoff RC, Collins CE, Morgan PJ. Maternal and paternal parenting practices and their influence on children's adiposity, screen-time, diet and physical activity. Appetite. 2014;79:149-157. PubMed ID: 24751915 doi:10.1016/j.appet.2014. 04.010

34. Zahra J, Sebire SJ, Jago R. "He's probably more Mr. sport than me"- a qualitative exploration of mothers' perceptions of fathers' role in their children's physical activity. BMC Pediatr. 2015;15:101. PubMed ID: 26306617 doi:10.1186/s12887-015-0421-9 